OPEN ACCESS

Edited by:

Sabine Dagmar Zimmermann, Délégation Languedoc Roussillon (CNRS), France

Reviewed by: Karine Mandon,

Université Côte d'Azur, France

Fabienne Cartieaux,

Institut de Recherche Pour le Dévelopment (IRD), France

${ }^{*}$ Correspondence: Ivan J. Oresnik

Ivan.Oresnik@umanitoba.ca

Specialty section:

This article was submitted to Plant Symbiotic Interactions, a section of the journal

Frontiers in Plant Science

Received: 15 October 2021

Accepted: 02 December 2021

Published: 03 January 2022

Citation:

Hawkins JP and Oresnik IJ (2022) The Rhizobium-Legume Symbiosis:

Co-opting Successful Stress Management.

Front. Plant Sci. 12:796045. doi: 10.3389/fpls.2021.796045

\section{The Rhizobium-Legume Symbiosis: Co-opting Successful Stress Management}

\author{
Justin P. Hawkins and Ivan J. Oresnik* \\ Department of Microbiology, University of Manitoba, Winnipeg, MB, Canada
}

The interaction of bacteria with plants can result in either a positive, negative, or neutral association. The rhizobium-legume interaction is a well-studied model system of a process that is considered a positive interaction. This process has evolved to require a complex signal exchange between the host and the symbiont. During this process, rhizobia are subject to several stresses, including low $\mathrm{pH}$, oxidative stress, osmotic stress, as well as growth inhibiting plant peptides. A great deal of work has been carried out to characterize the bacterial response to these stresses. Many of the responses to stress are also observed to have key roles in symbiotic signaling. We propose that stress tolerance responses have been co-opted by the plant and bacterial partners to play a role in the complex signal exchange that occurs between rhizobia and legumes to establish functional symbiosis. This review will cover how rhizobia tolerate stresses, and how aspects of these tolerance mechanisms play a role in signal exchange between rhizobia and legumes.

Keywords: rhizobium, legume, symbiosis, stress, pH, osmolarity, oxygen, ROS

\section{INTRODUCTION}

Rhizobia-legume symbiosis is a well-studied interaction which results in the formation of a plant derived organelle for the purposes of symbiotic nitrogen fixation. Establishment of this interaction occurs through a complex signal exchange which is initiated by the secretion of plant derived flavonoids that are then recognized by compatible rhizobia species (Oldroyd and Downie, 2008; Oldroyd et al., 2011). Recognition of flavonoids results in the production of a lipo-chito-oligosaccharide termed Nod factor (NF) which can be perceived by the host legume (Barnett and Fisher, 2006). This triggers calcium spiking in the inner plant cortical cells, resulting in the division of cells which will form the nodule primordia (Ehrhardt et al., 1996; Shaw and Long, 2003). Nod factor recognition also leads to root hair curling which can trap attached rhizobia and form a curled colonized root hair (Fournier et al., 2008). Infection thread formation can be observed after signals, such as exopolysaccharides or lipopolysaccharides, are recognized. This structure penetrates down toward nodule primordial cells where rhizobia become endocytosed into the cells and enclosed in a symbiotic membrane (Jones et al., 2007). Rhizobia then become bacteroids, which may or may not be terminally differentiated, that functionally serve as a plant organelle to reduce atmospheric nitrogen into ammonia which is subsequently utilized by the host legume.

While the signaling events that lead to an effective symbiosis are complex, other factors also play a major role in the establishment of an effective symbiosis. During the infection and differentiation process, rhizobia are challenged by numerous stresses, both in the rhizosphere 
and in planta (Figure 1). To tolerate the stresses that are encountered, bacteria produce compounds or change their lifestyle in order to permit survival. In numerous cases, these changes are correlated with the ability to establish a functional symbiosis. Molecules involved in plant pathogen recognition may also be necessary for symbiotic establishment, and in fact may serve as a signal to the bacteria to produce symbiotic signals. The focus of this work is to review aspects of rhizobia and plant responses to stress, and how elements of these responses may have become co-opted as signals involved in establishing a functional symbiosis.

\section{FLAVONOIDS}

The symbiotic interaction between legumes and rhizobia initiates when flavonoids are recognized by bacteria. The biosynthesis of flavonoids in plants is well understood (Ferrer et al., 2008), and to date, thousands of different flavonoids have been isolated. The biochemical diversity of flavonoids is achieved through modification of a limited number of base structures. These molecules play diverse roles in plant biology ranging from affecting flower color, auxin transport, and anti-microbial defenses (Winkel-Shirley, 2001).

Flavonoids are a known anti-microbial (Hassan and Mathesius, 2012) and represent one of the first directed challenges from plant toward bacteria. The production of these molecules is known to be induced in response to pathogen invasion and has been shown to be directly involved in the plant defense response (Cramer et al., 1985). One subgroup of flavonoids called the iso-flavonoids are found exclusively in legumes (Hirsch et al., 2001). Iso-flavonoids were originally thought to be involved in the defense response against fungi and were shown to also have toxic effects on some isolated bacteria. However, it has

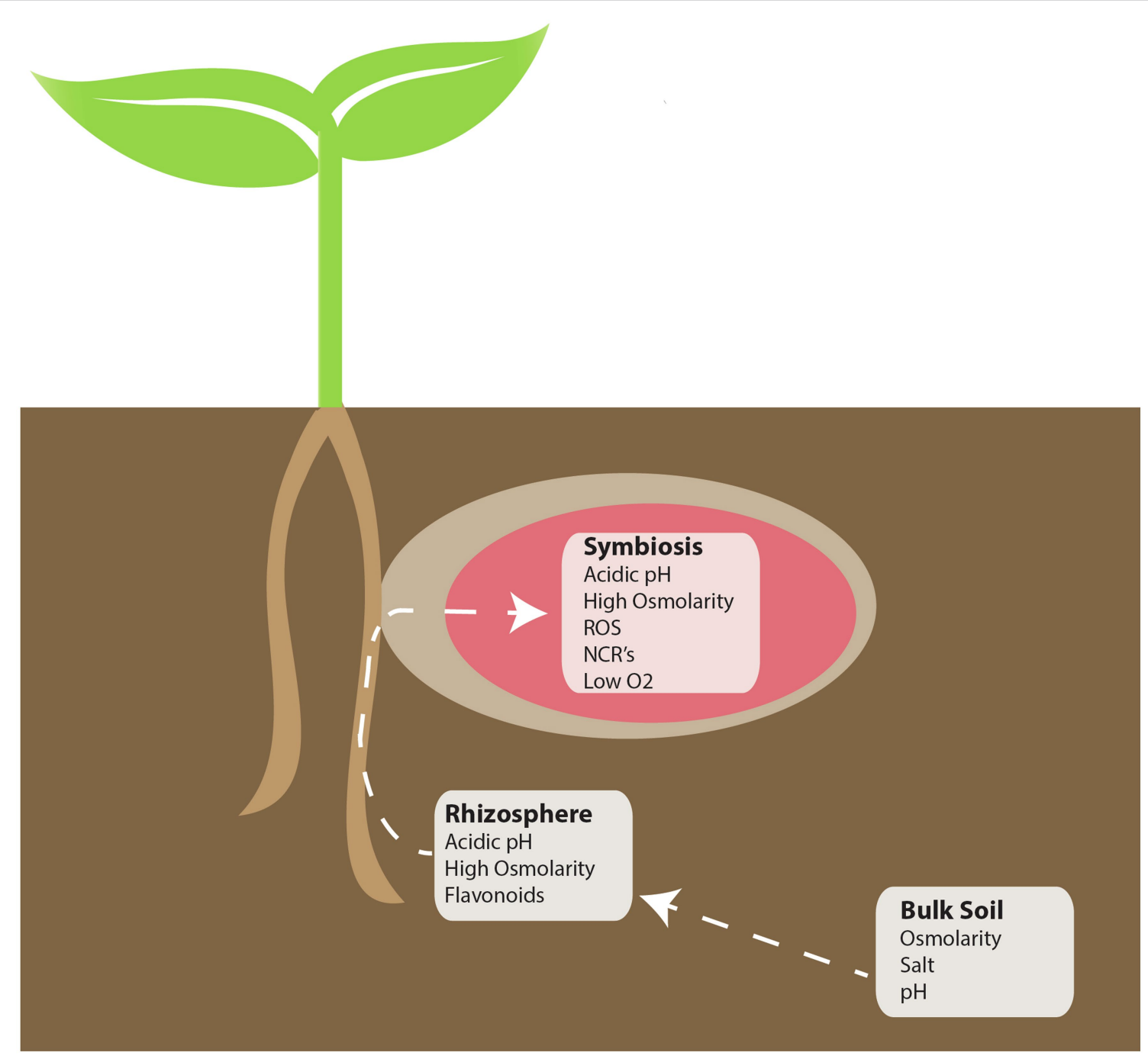

FIGURE 1 | Locations of perceived stress during the rhizobia-legume symbiosis. During symbiosis, there are three distinct environments that symbiotic bacteria must contend with: Bulk soil, the rhizosphere, and in planta. Each white box indicates potential "perceived" stressors that may be encountered in each of the indicated environments. 
also been shown that iso-flavonoids play a role in rhizobiumlegume symbiosis. Rhizobia which were exposed to purified iso-flavonoids from plant root exudates were shown to induce the transcription of nodABC, which encode proteins necessary for NF synthesis (Hartwig et al., 1990).

Secretion of the flavone luteolin which is produced by Medicago sativa has been shown to occur in distinct areas of the developing root where symbiotic interactions may occur (Ehrhardt et al., 1992). Flavones and isoflavones were also found to induce transcription of the nod genes in other rhizobia, and recognition of specific flavonoids was shown to play a role in plant-host specificity during symbiosis. Collectively, it seems that the initial role for flavonoids and iso-flavonoids secreted by plants was to be an anti-microbial (Cowan, 1999). However, rhizobia have been able to utilize very specific portions of flavonoids, the iso-flavonoids, as a signal indicating the presence of a compatible host and respond through the production of Nod factor to initiate symbiotic signaling.

\section{NOD FACTOR}

Signaling between host plants and symbiotic rhizobia or mycorrhizae share a common subset of genes and follow a similar pathway (Duc et al., 1989; Oldroyd, 2013). Each organism produces a lipo-chito-oligosaccharide ( $m y c /$ nod factor) that is recognized by LysM type receptors on the plant (Chabaud et al., 2002; Geddes and Oresnik, 2016). Mycorrhizal symbiosis is thought to be an ancient process and able to occur with most land-based plants, with the oldest symbiotic interaction known to be with the phylum Glomeromycota (Oldroyd, 2013). The secretion of $m y c$ factor, which is structurally similar to nod factor, is essential to its symbiotic interaction with its host plants. Comparatively, rhizobial symbiosis is relatively new and only occurs with legumes and Parasponia plants through recognition of NF by LysM type receptors (Pueppke and Broughton, 1999; Madsen et al., 2003). The similarities of the signaling pathway, and insights into Parasponia symbiotic signaling, has led to the hypothesis that the use of Nod factor for symbiosis evolved from myc factor signaling in mycorrhiza (Streng et al., 2011).

The structure of NF is comprised of 3-5 $\beta(1-4)$-linked $\mathrm{N}$-acetylglucosamine residues, with a fatty acid tail on the first residue, and can have various modifications to the $\mathrm{N}$-acetylglucosamine residues (Mylona et al., 1995). Nod factor is structurally similar to fungal cell wall chitin, which is a known activator of the plant immune response (Pusztahelyi, 2018). In addition, both Nod factor and chitin are recognized by LysM type receptors which are thought to have evolved from an ancestral LysM receptor (Zipfel and Oldroyd, 2017). The key difference being that Nod factor contains shorter $\mathrm{N}$-acetylglucosamine chain lengths. In the S. meliloti $-M$. truncatula model NF is recognized by the LysM receptors MtNFP and MtLYK3 (Oldroyd, 2013). This recognition induces numerous responses from $M$. truncatula which are necessary for successful symbiotic establishment. Transcriptomic studies have also revealed that Nod factor recognition regulates genes involved in the plant immune response (El-Yahyaoui et al., 2004). Studies have also shown that isolated Nod factor from rhizobia can modulate the immune response of both legumes and non-legumes. When Arabidopsis thaliana is exposed to the known pathogen associated molecular pattern flg22, the innate immune response of the plant becomes induced. Interestingly, when purified NF isolated from B. japonicum was applied, in addition to flg22, a more attenuated immune response was observed (Liang et al., 2013). This suggested that Nod factor-mediated suppression of the plants innate immune system may be necessary for successful colonization of plants.

Nod factor is also known to activate the innate defense responses from plants. Transcriptomic studies indicate that the plant immune response is initially activated due to $S$. meliloti inoculum (Lohar et al., 2006). Purified Nod factor has also been shown to induce the production of ROS in the nodulation zone of M. truncatula roots (Ramu et al., 2002). Further studies revealed that increased production of $\mathrm{H}_{2} \mathrm{O}_{2}$ can be observed to occur around root hair tips during Nod factor exposure (Cardenas et al., 2008). Interestingly, S. meliloti mutant strains over-expressing catalase also exhibited slower nodulation and malformed infection threads (Jamet et al., 2007). This suggests that while the suppression of the plant immune system is necessary for growth of rhizobia during symbiotic establishment, the initial immune response may bring about changes to both plant and bacteria that promote symbiosis. It has been suggested that the presence of $\mathrm{H}_{2} \mathrm{O}_{2}$ might be necessary for stabilizing the formation of infection threads or promoting a physiological change in rhizobia which would promote symbiosis (Jamet et al., 2007). These observations from early signaling involving the interplay of flavonoids and Nod factor production are a clear example of how a potential stress, flavonoids, induce a bacterial signal, Nod factor, that have become a key component for symbiotic interaction.

\section{ENVIRONMENTAL CONDITIONS}

The aforementioned topics on symbiotic signaling and regulation of the plant immune response provide a clear example of how tolerance of a stress has become intertwined in signaling. However, it is also important to consider how physiological conditions during symbiotic establishment may also promote symbiosis. Bacteria encounter a wide variety of conditions in both bulk soil and in planta. Bulk soil conditions can vary significantly around the world. In addition, the environment in planta can challenge bacteria with changes in osmolarity, oxygen content and oxidative stress, decreasing $\mathrm{pH}$, and further plant peptide challenges. The following points investigate how these conditions can promote physiological changes necessary for stress tolerance that end up influencing symbiotic establishment or nitrogen fixation (Table 1).

\section{OSMOTIC STRESS}

Genes involved in adaptation to varying osmotic conditions have been shown to be critical for the establishment of a 
TABLE 1 | Bacterial and plant changes due to perceived stress and their role in symbiosis.

\begin{tabular}{|c|c|c|}
\hline Stress & Response & Symbiotic relevance \\
\hline Bacteria/Pathogen & $\begin{array}{l}\text { Flavonoid } \\
\text { NCRs } \\
\text { Innate immune response }\end{array}$ & $\begin{array}{l}\text { Nod factor induction } \\
\text { Bacteroid differentiation } \\
\text { Oxidative burst (see ROS) }\end{array}$ \\
\hline Flavonoid & Nod factor & Calcium spiking \\
\hline Salt/lon stress & $\begin{array}{l}\text { Nod factor } \\
\text { EPS-I }\end{array}$ & $\begin{array}{l}\text { Calcium spiking } \\
\text { IT development }\end{array}$ \\
\hline Osmotic & $\begin{array}{l}\text { cyclic } \beta(1-2) \text { glucans } \\
\text { Intracellular Potassium } \\
\text { concentration }\end{array}$ & $\begin{array}{l}\text { Attachment/ IT formation } \\
\text { Nitrogenase induction }\end{array}$ \\
\hline Acidic $\mathrm{pH}$ & $\begin{array}{l}\text { actR/S } \\
\text { exoR/S/I } \\
\text { Nod factor profile }\end{array}$ & $\begin{array}{l}\text { fixK/nifA } \\
\text { EPS-I } \\
\text { Legume host range }\end{array}$ \\
\hline Reactive oxygen species & $\begin{array}{l}\text { EPS-I } \\
\text { Membrane crosslinking }\end{array}$ & $\begin{array}{l}\text { IT development } \\
\text { IT development }\end{array}$ \\
\hline Low oxygen & $\begin{array}{l}\text { Intracellular potassium } \\
\text { Fix genes } \\
\text { LPS modification }\end{array}$ & $\begin{array}{l}\text { Nitrogenase induction } \\
\text { Nitrogenase induction } \\
\text { Legume host range }\end{array}$ \\
\hline
\end{tabular}

functional symbiotic relationship. Osmotic conditions before symbiosis are fully dependent on salts and exudates present in the soil. Bulk soil is generally assumed to be an area of low osmolarity (Miller and Wood, 1996). However, the area of the rhizosphere is predicted to have a higher osmolarity due to plant root exudate and water uptake from both plants and bacteria (Jungk, 2002; Miller-Williams et al., 2006). While the osmotic conditions throughout symbiosis in the rhizobialegume interaction are unknown, current research is consistent with the hypothesis that both high and low osmolarity conditions exist throughout symbiosis (Botsford and Lewis, 1990; Dylan et al., 1990a). The area of the rhizosphere having high osmolarity is particularly interesting as these conditions have been linked with inducing genes necessary for symbiosis. The presence of high osmotic conditions has been shown to induce transcription of genes involved in nodulation and nitrogen fixation (nod, nif, and fix genes) through NodD2 in Rhizobium tropici CIAT 899 (Del Cerro et al., 2019). This same pattern of regulation of these genes through NodD2 is also observed when $R$. tropici is exposed to increased salt stress present in the rhizosphere (Pérez-Montaño et al., 2016). In addition, increased salt concentrations are known to regulate exopolysaccharide production in S. meiloti (Miller-Williams et al., 2006). These observations provide the most direct link between osmotic stress recognition and promoting symbiosis.

The major link between osmotic stress tolerance and physiological changes with importance to symbiosis is the accumulation of periplasmic glucans in the presence of hypotonic stress. The majority of the organisms in the family Rhizobiaceae produces a cyclic $\beta(1-2)$-linked glucan (York et al., 1980; Lelpi et al., 1990; Breedveld and Miller, 1994). Accumulation of these periplasmic glucans can be observed when grown under hypotonic conditions (Miller et al., 1986; Dylan et al., 1990a; Breedveld and Miller, 1995). Further study of cyclic $\beta(1-2)$ glucans in $S$. meliloti determined that the inability to produce this polysaccharide, by mutating the gene $n d v B$, resulted in sensitivity to hypotonic conditions, and abolished nodule formation on M. truncatula (Dylan et al., 1990b). It was hypothesized that extracellular cyclic $\beta(1-2)$ may be involved in root attachment, but addition of purified cyclic $\beta(1-2)$ was unable to restore symbiosis with $M$. truncatula to a $n d v B$ mutant strain (Dylan et al., 1990b). Pseudorevertants of the $n d v B$ mutant strain that still did not produce the cyclic glucan have been isolated and were found to be able to establish a functional symbiosis with $M$. truncatula. However, these suppressors were still heavily impacted in infection thread formation and were sensitive to hypoosmotic stress (Dylan et al., 1990b). This suggested that while cyclic $\beta(1-2)$ glucan production is important for osmotic stress tolerance and can be linked to infection thread formation, their role in symbiosis extends past stress tolerance. Suppression of the symbiotic phenotype of $n d v B$ mutants was later linked to the production the symbiotically important polysaccharide succinoglycan (Nagpal et al., 1992).This lead to the suggestion that production of succinoglycan might provide just enough osmoprotectant in the form of low molecular weight succinoglycan to allow for survival in the absence of the cyclic glucans. In addition, succinoglycan may provide or mask a signal necessary for symbiosis in the absence of cyclic glucans (Abe et al., 1982; Nagpal et al., 1992). Overall, osmolarity is involved in regulating cyclic $\beta(1-2)$ glucans which have a role in symbiosis that extends past stress tolerance.

Another mechanism rhizobia and other bacteria utilize to tolerate high osmolarity is the accumulation of ions, such as potassium (Yancey et al., 1982; Csonka, 1989; Botsford and Lewis, 1990; Smith et al., 1994; Miller and Wood, 1996). Interestingly, increased potassium levels lead to an increase in nitrogenase activity in Bradyrhizobium sp. $32 \mathrm{H} 1$ when grown under low oxygen conditions (Gober and Kashket, 1987). As the bacteroid is predicted to be an area of elevated osmotic stress (Miller and Wood, 1996), this provides a link showing that osmotic stress tolerance may be a signal for the regulation of nitrogenase in the bacteroid through the regulation of potassium concentration.

\section{LOW OXYGEN CONTENT}

During symbiotic establishment, rhizobia encounter areas of low oxygen concentration in the nodule. Control of oxygen concentration is important for symbiosis since oxygen inhibits the activity of nitrogenase (Hunt and Layzell, 1993). Oxygen levels are controlled through a diffusion barrier to create optimal oxygen concentrations for nitrogen fixation (Hunt et al., 1987). Tight regulation of oxygen concentration in bacteroids also leads to a number of signaling and physiological changes in bacteria, which promote symbiosis and nitrogen fixation. It has been well documented that a low oxygen concentration activates the two-component system FixJL, which in turn increases the transcription of the majority of genes involved in nitrogen fixation (David et al., 1988; Virts et al., 1988). Recent work has shown that there are 3 proteins that act oxygen sensors in Rhizobium leguminosarum; hFixL, FnrN, and 
NifA (Dixon and Kahn, 2004; Zamorano-Sánchez and Girard, 2015; Reyes-González et al., 2016). These proteins are tightly temporally controlled, with hFixL inducing expression of FnrN in zones I and II (meristem zone and invasion zone, respectively) of indeterminate nodules. FnrN then induces expression of fixNOQP in zone III (nitrogen fixing zone) when oxygen concentration is near anaerobic (Rutten et al., 2021). The induction the genes necessary for production of nitrogenase in near anaerobic conditions is necessary for function of the protein and is also a clear example of how microaerobic stress acts as a signal for symbiosis.

Oxygen concentration has also been shown to regulate lipopolysaccharide (LPS) synthesis and decoration (Kannenberg and Brewin, 1989; Tang and Hollingsworth, 1998). This is thought to have a role in adaptation to the low oxygen environment. Production and modification of LPS are strain specific and are involved in determining host range for symbiosis in some rhizobia (Via et al., 2016). The ability to produce, or properly modify, LPS has been linked to defects in symbiotic establishment (Keating et al., 2002). As LPS content and decoration are dynamic based upon its environment, it is expected that LPS modification would change during symbiosis. Recent work has also shown that flavonoids can induce changes in decoration of LPS and that these changes are necessary for symbiosis (Broughton et al., 2006). It is possible that low oxygen concentration might contribute to bringing about a change in LPS production and decoration which is necessary for both symbiosis and survival in these conditions.

\section{REACTIVE OXYGEN SPECIES}

In addition to low oxygen concentration, rhizobia encounter reactive oxygen species as part of the innate immune response of the plant, and it can be found throughout symbiotic compartments ranging from the IT to mature nodules (Santos et al., 2001). Formation of ROS from the plant immune response has been shown to be beneficial for symbiotic establishment (Puppo et al., 2013). ROS are generated upon Nod factor recognition and are thought to predominantly occur from the activity of NADPH oxidase (Lohar et al., 2007). Rhizobia utilize a number of mechanisms to deal with potential damage from ROS (Boscari et al., 2013). The importance of ROS scavenging during symbiosis is highlighted by the finding that strains which carry mutations in the genes $k a t B / C$, which encode for catalases, are impaired in forming bacteroids (Jamet et al., 2003). However, a positive role for ROS in symbiosis has also been observed. When catalase is over-expressed in S. meliloti, aberrant IT formation and delayed nodule development are observed (Jamet et al., 2007). While it is unknown exactly how ROS may contribute to symbiosis, two main suggestions have been made; either ROS plays a role in IT development, or ROS induces physiological changes in rhizobium that are necessary for symbiosis (Pauly et al., 2006). Recent work has investigated this further and has shown that ROS produced by PvRbohB in Phaseolus vulgaris is important for symbiosis. Cultivars of $P$. vulgaris silenced in expression of PvRbohB displayed abortive infection threads when inoculated with R. tropici (Fonseca-García et al., 2021). RNAseq data also revealed changes in carbon metabolism and cell cycle control; both of which can be linked with symbiosis (Geddes and Oresnik, 2016; Fonseca-García et al., 2021).

Consistent with the hypothesis that ROS may act as a signal to bacteria for symbiotic establishment, it has been shown B. japoncium exposed to oxidative stress produces an increased amount of exopolysaccharides (Donati et al., 2011). The production of exopolysaccharides (EPS) has long been suggested to be involved in the tolerance of various stresses encountered by bacteria. In $S$. meliloti and Pseudomonas syringae, mutants unable to produce EPS have been observed to be sensitive to ROS (Király et al., 1997; Lehman and Long, 2013). Furthermore, it was shown that low molecular weight succinoglycan (EPS-I) is the responsible fraction which scavenges $\mathrm{H}_{2} \mathrm{O}_{2}$ from media in S. meliloti (Lehman and Long, 2013). Taken together, oxidative stress is seen to promote the production of exopolysaccharides which are necessary for the tolerance of ROS and critical for symbiotic establishment. Since plants are observed to produce $\mathrm{H}_{2} \mathrm{O}_{2}$ in response to symbiotic establishment, this provides a potential example of how in planta conditions promote production of a symbiotic signal.

\section{pH STRESS}

The ability to tolerate acidic $\mathrm{pH}$ conditions has largely been studied from the perspective of tolerating acidic soils in the environment. The area of the rhizosphere is predicted to be an area of increased acidic stress, as throughout their life cycle, plants can excrete acidic compounds into the surrounding soil, decreasing the $\mathrm{pH}$ of the soil by as much as $2 \mathrm{pH}$ units (Faget et al., 2013). This occurs from the secretion of protons to maintain the net charge across the root membrane and from the secretion of organic compounds (Jones et al., 2003). During the symbiotic interaction between rhizobia and legumes, it has been hypothesized that many plant derived compartments have an acidic $\mathrm{pH}$. The bacteroid and peri-bacteroid space have been predicted to be an acidic compartment, reaching a pH of 4.5 (Fedorova et al., 1999; Pierre et al., 2013). Studies have also determined that the curled colonized root hair is an area of localized acidic pH stress (Geddes et al., 2014). These findings are particularly important as $S$. meliloti is known to have poor survival when medium $\mathrm{pH}$ decreases below six (Hellweg et al., 2009; Hawkins et al., 2017).

Transcriptomic studies addressing the response of rhizobium to acidic $\mathrm{pH}$ and have revealed large networks regulating multiple genes in response to acidic pH (Hellweg et al., 2009; Guerrero-Castro et al., 2018). The response of rhizobia to acidic $\mathrm{pH}$ is primarily regulated though two-component systems, actR/S and chvI/exoS/exoR (Dilworth et al., 2000; Fenner et al., 2004). These systems ultimately control the regulation of cytoplasmic $\mathrm{pH}$, or the production of and modification of extracellular elements for $\mathrm{pH}$ tolerance components (Cunningham and Munns, 1984; Chen et al., 1993). Regulation of potassium efflux proteins is important for $\mathrm{pH}$ tolerance. The potassium 
efflux system in $R$. tropici has been shown to be regulated by glutathione, since mutants in glutathione synthesis were unable to accumulate intracellular potassium (Riccillo et al., 2000). Potassium concentrations have been shown to regulate nitrogenase activity so this accumulation of $\mathrm{K}^{+}$in acidic conditions may act as a symbiotic signal (Gober and Kashket, 1987). In addition, glutathione is involved in tolerating many environmental stressors, including $\mathrm{pH}$ and ROS stress, and has been shown to be produced in increased amounts under acidic conditions (Riccillo et al., 2000; Muglia et al., 2007). Mutations in the synthesis pathway for glutathione are known to result in either a fix ${ }^{-}$or delayed nodulation phenotype (Harrison et al., 2005).

One physiological response of $S$. meliloti to low $\mathrm{pH}$ is the production of the symbiotically important exopolysaccharide EPS-I (Hawkins et al., 2017). Acidic pH is known to be present throughout the symbiotic process, being present in the rhizosphere all the way to bacteroids. Mutants which are unable to produce succinoglycan are unable to establish functional symbiosis with alfalfa. Further investigation has revealed that the succinylation of EPS-I is the critical component of the symbiotic interaction (Mendis et al., 2016). Production of EPS-I is also important for tolerance of low $\mathrm{pH}$ and contributes to survival in nodules (Hawkins et al., 2017; Maillet et al., 2020). However, symbiotic defects observed in exo mutant strains are likely due to a combination of a loss of $\mathrm{pH}$ stress tolerance and loss of proper symbiotic signaling. S. meliloti strains that lack exoK produce a succinylated high molecular weight EPS-I still exhibit high sensitivity to acidic $\mathrm{pH}$, but only display minor symbiotic defects (Maillet et al., 2020). Collectively, these data suggest that EPS-I plays a role in both stress tolerance as well as symbiotic signaling.

It has also been observed that acid tolerant strains of rhizobia produce more exopolysaccharides than acid sensitive strains under non-stress conditions (Cunningham and Munns, 1984). Interestingly, mutations that resulted in an increased production of exopolysaccharide in $R$. leguminosarum and S. meliloti did not result in an increased tolerance to acidic media (Howieson et al., 1988; Reeve et al., 1997). These observations suggest that in terms of stress tolerance, the production of exopolysaccharides may serve an on/off function rather than a gradient of tolerance, and that the increased production of exopolysaccharides due to $\mathrm{pH}$ stress may have another role.

The response to low $\mathrm{pH}$ is largely mediated through the ExoR/ ExoS/ChvI (RSI) system, which has been shown to be upregulated due to acidic $\mathrm{pH}$ in S. meliloti (Hellweg et al., 2009; Draghi et al., 2016). The RSI system is well studied for its ability to regulate the production of EPS-I and flagella (Cheng and Walker, 1998b; Heavner et al., 2015). It is long known that the production of EPS-I is important for symbiotic interaction (González et al., 1996; York and Walker, 1997; Cheng and Walker, 1998a). The protein ExoS acts as a sensor kinase which directly phosphorylates the response regulator ChvI in response to a signal (Cheng and Walker, 1998b; Yao et al., 2004). This system is regulated through direct binding of the repressor ExoR to ExoS in the periplasm (Chen et al., 2008). Homologs of this system in Agrobacterium tumefaciens have been shown to be involved in gene regulation due to acidic $\mathrm{pH}$, and it has been suggested that acidity is a key signal in establishing virulence with plants (Li et al., 2002). Further study of the RSI regulon in A. tumefaciens has revealed that at acidic $\mathrm{pH}$ the repressor ExoR is degraded, resulting in increased EPS-I synthesis (Heckel et al., 2014). A mechanism for degradation of ExoR in S. meliloti has also been shown (Lu et al., 2012). Degradation of ExoR could account for the increase in transcription of exoR at lower $\mathrm{pH}$. Taken together, this suggests that the acidic conditions found in the curled colonized root hair leads to the production of EPS-I which is necessary for symbiotic signaling and stress tolerance, making $\mathrm{pH}$ a key environmental regulator for symbiosis. Overall, these works suggest that low $\mathrm{pH}$ induces the production of glutathione and succinoglycan which are both involved in stress tolerance and symbiosis.

\section{NODULE-SPECIFIC CYSTEINE RICH PEPTIDES}

Recently, there has been interest in a subsect of plant produced anti-microbial peptides (AMPs) called nodule-specific cysteine rich (NCR) peptides for their role in symbiotic establishment (Alunni and Gourion, 2016). AMPs are well studied for their anti-microbial activity (Maroti et al., 2011). The mechanism of action of AMPs involves the disruption of bacterial membranes through interaction with the cell surface and ribosome inactivation. In addition to their anti-microbial activity, it has been suggested that certain AMPs play a role in signaling (Schopfer, 1999).

NCRs are structurally and functionally similar to AMPs; they are predicted to be around 100 amino acids long, contain the conserved cysteine residues for disulfide bridge formation, and are predicted to be largely cationic (Mergaert et al., 2003). These peptides have also been shown to have anti-microbial activity against several organisms, including rhizobia (Haag et al., 2011). However, the presence of the protein BacA in S. meliloti, a transporter for AMPs, is observed to be involved in tolerating the challenge with NCRs, whereas mutants in bacA were observed to be hypersensitive to the anti-microbial activity in planta (Haag et al., 2011).

In M. truncatula, there are predicted to be upwards of 300 different NCRs produced by around 600 different genes (Mergaert et al., 2003; Zhou et al., 2013). Only legumes of the invertedrepeat lacking clade (IRLC) are observed to produce NCRs (Mergaert et al., 2006). In these legumes, symbiotic bacteria become terminally differentiated into bacteroids in plant nodules and cannot revert to normal functioning bacteria. Non-IRLC legumes, such as $L$. japonicus, do not produce NCRs, and symbiotic bacteria do not become terminally differentiated (Mergaert et al., 2003). This has led to the suggestion that NCRs are directly involved in the terminal differentiation of symbiotic bacteria. However, it is worth noting that examples of bacteroid differentiation outside of the IRLC legumes are starting to be found. Nodules formed in the Aeschynomene Bradyrhizobium symbiotic relationship are found to house differentiated bacteroids with a polyploid genome (Czernic et al., 2015). While Aeschynomene sp. do not produce NCRs they have been shown to produce NCR-like peptides that likely play a role in differentiation of bacteroids. Silencing the homolog of 
dnf1 in Aeschynomene evenia, which is necessary for cleavage of NCRs for transport to the symbiosome and is essential for symbiosis, results in deformed bacteroids (Czernic et al., 2015). In addition, the protein BclA was identified in Bradyrhizobium $s p$. as having weak homology to BacA. BclA was shown to be necessary for formation of bacteroids and was observed to be able to transport the peptide NCR247 from M. truncatula (Guefrachi et al., 2015). Taken together, there is good indirect evidence that these NCR-like peptides are used for bacteroid differentiation.

The localization of NCRs suggests much about their role in symbiosis. When NCRs are expressed in the nodule, they are targeted to the symbiotic membrane by the plant secretory system and can also be found within the cytoplasm of bacteroids (Van de Velde et al., 2010). In the same study, it was also shown that a mutation in $M$. truncatula $d n f-1$ prevents targeting of NCRs to the bacteroid and prevented bacteroids from terminally differentiating. Also, when NCR035 from M. truncatula was expressed in L. japonicum, which is deficient in NCR production, it localized to the symbiosome of bacteroids resulting in the production of a single elongated bacteroid indicative of terminal differentiation (Alunni et al., 2007; Van de Velde et al., 2010). This highlighted the importance of NCRs for symbiotic establishment in the IRLC legumes. More recent studies on NCRs have shown that a mutation in the gene $d n f 7$, which encodes for a protein involved in the production of NCR169, is unable to perform BNF in M. truncatula (Horváth et al., 2015). Nodules in this mutant were impaired in elongation and triggered early senescence. This was fully complemented by overexpression of NCR169. These studies show the necessity of NCRs in regulating bacteroid differentiation and symbiotic nitrogen fixation.

Microarray analysis has also revealed that NCR recognition may play a role in the bacterial stress response, as well as preventing cell division during symbiosis (Penterman et al., 2014). After exposure of S. meliloti to NCR247, the expression of genes involved in bacterial stress response and cellular division was found to be altered in transcription. This includes increased transcription of $r p o H 1$, which is involved in regulating genes for acid and heat tolerance, and the two-component systems exoS-chvI and feuP-feuQ, which are responsible for regulating EPS and cyclic $\beta(1-2)$ glucan production (Reuber et al., 1990; Griffitts et al., 2008). In line with this, NCR247 has been shown to induce transcription of the exo genes for EPS-I production, and high molecular weight EPS-I has been shown to aid survival when exposed to NCR247 (Arnold et al., 2017, 2018). Decreased transcription of cell cycle regulators ctrA and gcrA was also observed (Penterman et al., 2014). These observations led to the conclusion that NCR recognition may be a bacterial signal that allows for adaptation to in planta conditions and increase the production of polysaccharides necessary for symbiosis in addition to its role in bacteroid differentiation. This shows that NCRs may have evolved in plants from simply being an AMP produced as a response to bacterial invasion, to also being involved in symbiotic establishment as a signal which induces physiological and morphological changes in the bacteria necessary for nitrogen fixation.



\section{DISCUSSION}

The establishment of the rhizobium - legume symbiotic interaction is often described as a direct complex signal exchange between both the bacteria and the plant, with emphasis placed on how a molecule from one induces changes in the other or invokes a signaling response. However, little emphasis has been placed on how environmental conditions and stress tolerance play into the interaction. Here, we provide evidence that the tolerance of environmental conditions and challenges by the plant immune system result in alterations of bacterial physiology which promotes establishment of symbiosis between plant and bacteria. This broadens our assumptions of the signaling cross-talk between legume and rhizobia which is 
largely considered from the perspective of secreted signal and direct response. In addition, we should consider overall physiological changes in bacteria due to conditions in the soil from root exudate or in planta as part of the signal exchange symbiosis in addition to the role in surviving the stress conditions. If molecules produced as part of the stress response by bacteria and plant are examined it can be seen that stress plays an important role from the start of symbiosis, all the way to nitrogen fixation (Figure 2).

Some of the examples used are already well studied for their role specifically in symbiosis. This includes iso-flavonoids, Nod factor, and NCRs. While these molecules now have roles directly in symbiotic signaling, their overall origin in this process comes from the immune response of the plant. What likely originated as a stress challenge of anti-microbials for bacteria and fungi with flavonoids and NCRs has turned into critical signals to initiate the symbiotic process or for forming terminally differentiated bacteroids. Cell wall chitin from fungi which is recognized as a PAMP has become inherited by rhizobia in the form of Nod factor, which is now the critical signaling molecule secreted by bacteria to establish symbiosis. The similarities of the responses between either plant immunity or symbiosis are significant and stretch much further past what is discussed here (Berrabah et al., 2015; Tóth and Stacey, 2015; Zipfel and Oldroyd, 2017). It is quite likely that as more detailed mechanisms of each of these responses are uncovered, it will be seen that there is significant cross-talk or similarities linking stress responses and symbiosis. In a number of cases, the difference between either killing the bacteria or establishing a functional symbiosis seems to be based upon the strength of the plant immune response to the organism. A strong response to repel an invader, or an attenuated one to induce physiological changes in a potential symbiont.

Other examples of how potential conditions bacteria may be exposed to in the soil or in planta are less directly tied to symbiosis, but the link is still quite clear. A large part of the stress response of symbiotic rhizobia revolves around production or modification of various polysaccharides, such as cyclic $\beta(1-2)$ glucans, lipopolysaccharides, and succinoglycan. These polysaccharides are also intrinsically linked to symbiotic establishment across a number of different rhizobia-legume interactions. While the role of cyclic $\beta(1-2)$ glucans in symbiosis is yet unclear, production and proper decoration of LPS and succinoglycan are suggested to be critical signaling molecules to avoid the full activation of the plant immune response (Ojeda

\section{REFERENCES}

Abe, M., Amemura, A., and Higashi, S. (1982). Studies on cyclic $\beta$-1,2-glucan obtained from periplasmic space of rhizobium trifolii cells. Plant Soil 64, 315-324. doi: 10.1007/BF02372514

Alunni, B., and Gourion, B. (2016). Terminal bacteroid differentiation in the legume - rhizobium symbiosis: nodule-specific cysteine-rich peptides and beyond. New Phytol. 211, 411-417. doi: 10.1111/nph.14025

Alunni, B., Kevei, Z., Redondo-Nieto, M., Kondorosi, A., Mergaert, P., and Kondorosi, E. (2007). Genomic organization and evolutionary insights on GRP and NCR genes, two large nodule-specific gene families in Medicago truncatula. Mol. Plant Micro.Interact. 20, 1138-1148. doi: 10.1094/ MPMI-20-9-1138 et al., 2013; Kawaharada et al., 2015; Maillet et al., 2020). Additionally, there are around 17 different hypothetical operons for polysaccharide production in S. meliloti so it is plausible to think other polysaccharides that are yet unclassified may play an important role in the stress tolerance/symbiosis picture as well.

Aside from polysaccharide production, these adverse conditions encountered also changes cell physiology in terms of ion uptake, glutathione production, and shifts in carbon metabolism which can all be linked in some regards to the symbiotic process. It is not hard to imagine that symbiotic bacteria may have evolved its responses over time to stress conditions present in root exudate or in planta to start adjusting its physiology for a symbiotic lifecycle. In addition, it is understandable why a plant would evolve to promote certain conditions using root exudate and use an altered immune response if the eventual gain becomes a symbiotic nitrogen fixing bacteria.

One of the major overall goals of nitrogen fixation research is to eventually bring the symbiotic relationship between legumes and rhizobia to non-legume plants, such as the cereal crops. The potential impact this could have in reducing use of nitrogen fertilizers, and for overall growth of plants where fertilizers are not available, is quite significant. While research in this area is new and ongoing, it largely focuses on adjusting and tuning directly observed signaling between rhizobia and these plants. It is important to remember that aside from signaling and adjusting the plant's immune response to go from immunogenic to symbiotic, the overall environment in the rhizosphere and in planta may also play a key role for symbiosis and have to be accounted for. At the end of the day, it is always said that stress, unfortunately, is a great motivator in life. This also seems to be true with respect to the rhizobium-legume symbiosis.

\section{AUTHOR CONTRIBUTIONS}

JPH and IJO conceived and wrote the manuscript. All authors contributed to the article and approved the submitted version.

\section{FUNDING}

This work was supported by a Natural Sciences and Engineering Research Council of Canada Discovery grant (RGPIN-201804966) to IJO. 
Boscari, A., Meilhoc, E., Castella, C., Bruand, C., Puppo, A., and Brouquisse, R. (2013). Which role for nitric oxide in symbiotic $\mathrm{N}_{2}$-fixing nodules: toxic by-product or useful signaling/metabolic intermediate? Front. Plant Sci. 4:384. doi: $10.3389 /$ fpls.2013.00384

Botsford, J. L., and Lewis, T. A. (1990). Osmoregulation in rhizobium meliloti: production of glutamic acid in response to osmotic stress. Appl. Environ. Microbiol. 56, 488-494. doi: 10.1128/aem.56.2.488-494.1990

Breedveld, M. W., and Miller, K. J. (1994). Cyclic $\beta$-glucans of members of the family Rhizobiaceae. Microbiol. Rev. 58, 145-161. doi: 10.1128/mr.58.2.145-161.1994

Breedveld, M. W., and Miller, K. J. (1995). Synthesis of glycerophosphorylated cyclic $(1,2)$ - $\beta$-glucans in rhizobium meliloti strain 1021 after osmotic shock. Microbiology 141, 583-588. doi: 10.1099/13500872-141-3-583

Broughton, W. J., Hanin, M., Relic, B., Kopcinska, J., Golinowski, W., Simsek, S., et al. (2006). Flavonoid-inducible modifications to rhamnan $\mathrm{O}$ antigens are necessary for rhizobium sp. strain NGR234-legume symbioses. J. Bacteriol. 188, 3654-3663. doi: 10.1128/JB.188.10.3654-3663.2006

Cardenas, L., Martinez, A., Sanchez, F., and Quinto, C. (2008). Fast, transient and specific intracellular ROS changes in living root hair cells responding to nod factors (NFs). Plant J. 56, 802-813. doi: 10.1111/j.1365-313X.2008.03644.x

Chabaud, M., Venard, C., Defaux-Petras, A., Bécard, G., and Barker, D. G. (2002). Targeted inoculation of Medicago truncatula in vitro root cultures reveals MtENOD11 expression during early stages of infection by arbuscular mycorrhizal fungi. New Phytol. 156, 265-273. doi: 10.1046/j.1469-8137.2002.00508.x

Chen, H., Richardson, A. E., and Rolfe, B. G. (1993). Studies of the physiological and genetic basis of acid tolerance in rhizobium leguminosarum biovar trifolii. Appl. Environ. Microbiol. 59, 1798-1804. doi: 10.1128/aem.59.6.1798-1804.1993

Chen, E. J., Sabio, E. A., and Long, S. R. (2008). The periplasmic regulator ExoR inhibits ExoS/ChvI two- component signaling in Sinorhizobium meliloti. Mol. Microbiol. 69, 1290-1303. doi: 10.1038/jid.2014.371

Cheng, H. P., and Walker, G. C. (1998a). Succinoglycan is required for initiation and elongation of infection threads during nodulation of alfalfa by rhizobium meliloti. J. Bacteriol. 180, 5183-5191. doi: 10.1128/JB.180.19.5183-5191.1998

Cheng, H. P., and Walker, G. C. (1998b). Succinoglycan production by rhizobium meliloti is regulated through the ExoS-ChvI two-component regulatory system. J. Bacteriol. 180, 20-26. doi: 10.1128/JB.180.1.20-26.1998

Cowan, M. M. (1999). Plant products as antimicrobial agents. Clin. Microbiol. Rev. 12, 564-582. doi: 10.1128/CMR.12.4.564

Cramer, C. L., Ryder, T. B., Bell, J. N., and Lamb, C. J. (1985). Rapid switching of plant gene expression induced by fungal elicitor. Science 227, 1240-1243. doi: $10.1126 /$ science.227.4691.1240

Csonka, L. N. (1989). Physiological and genetic responses of bacteria to osmotic stress. Microbiol. Rev. 53, 121-147. doi: 10.1128/mr.53.1.121-147.1989

Cunningham, S. D., and Munns, D. N. (1984). The correlation between extracellular polysaccharide production and acid tolerance in rhizobium. Soil Sci. Soc. Am. J. 48, 1273-1276. doi: 10.2136/sssaj1984.03615995004800060014x

Czernic, P., Gully, D., Cartieaux, F., Moulin, L., Guefrachi, I., Patrel, D., et al. (2015). Convergent evolution of endosymbiont differentiation in Dalbergioid and inverted repeat-lacking clade legumes mediated by nodule-specific cysteine-rich peptides. Plant Physiol. 169, 1254-1265. doi: 10.1104/pp.15.00584

David, M., Daveran, M. L., Batut, J., Dedieu, A., Domergue, O., Ghai, J., et al. (1988). Cascade regulation of Nif gene-expression in rhizobium meliloti. Cell 54, 671-683. doi: 10.1016/S0092-8674(88)80012-6

Del Cerro, P., Megías, M., López-Baena, F. J., Gil-Serrano, A., Pérez-Montaño, F., and Ollero, F. J. (2019). Osmotic stress activates nif and fix genes and induces the rhizobium tropici CIAT 899 nod factor production via $\mathrm{NodD}_{2}$ by up-regulation of the nodA2 operon and the nodA3 gene. PLoS One 14:e0213298. doi: 10.1371/journal.pone.0213298

Dilworth, M. J., Tiwari, R. P., Reeve, W. G., and Glenn, A. R. (2000). Legume root nodule bacteria and acid pH. Sci. Prog. 83, 357-389.

Dixon, R., and Kahn, D. (2004). Genetic regulation of biological nitrogen fixation. Nat. Rev. Microbiol. 2, 621-631. doi: 10.1038/nrmicro954

Donati, A. J., Jeon, J. M., Sangurdekar, D., So, J. S., and Chang, W. S. (2011). Genome-wide transcriptional and physiological responses of Bradyrhizobium japonicum to paraquat-mediated oxidative stress. Appl. Environ. Microbiol. 77, 3633-3643. doi: 10.1128/AEM.00047-11

Draghi, W. O., Del Papa, M. F., Hellweg, C., Watt, S. A., Watt, T. F., Barsch, A., et al. (2016). A consolidated analysis of the physiologic and molecular responses induced under acid stress in the legume-symbiont model-soil bacterium Sinorhizobium meliloti. Sci. Rep. 6:e29278. doi: 10.1038/srep29278
Duc, G., Trouvelot, A., Gianinazzi-Pearson, V., and Gianinazzi, S. (1989). First report of non-mycorrhizal plant mutants (Myc-) obtained in pea (Pisum sativum L.) and fababean (Vicia faba L.). Plant Sci. 60, 215-222. doi: 10.1016/0168-9452(89)90169-6

Dylan, T., Helinski, D. R., and Ditta, G. S. (1990a). Hypoosmotic adaptation in rhizobium meliloti requires beta-(1-2)-glucan. J. Bacteriol. 172, 1400-1408. doi: $10.1128 /$ jb.172.3.1400-1408.1990

Dylan, T., Nagpal, P., Helinski, D. R., and Ditta, G. S. (1990b). Symbiotic pseudorevertants of rhizobium meliloti ndv mutants. J. Bacteriol. 172, 1409-1417. doi: 10.1128/jb.172.3.1409-1417.1990

Ehrhardt, D. W., Atkinson, E. M., and Long, S. R. (1992). Depolarization of alfalfa root hair membrane potential by rhizobium meliloti nod factors. Science 256, 998-1000. doi: 10.1126/science.10744524

Ehrhardt, D. W., Wais, R., and Long, S. R. (1996). Calcium spiking in plant root hairs responding to rhizobium nodulation signals. Cell 85, 673-681. doi: 10.1016/S0092-8674(00)81234-9

El-Yahyaoui, F., Kuster, H., Amor, B. B., Hohnjec, N., Pu, A., Becker, A., et al. (2004). Expression profiling in Medicago truncatula pdentifies more than 750 genes differentially expressed during nodulation, including many potential regulators of the symbiotic program. Plant Physiol. 136, 3159-3176. doi: 10.1104/pp.104.043612.the

Faget, M., Blossfeld, S., von Gillhaussen, P., Schurr, U., and Temperton, V. M. (2013). Disentangling who is who during rhizosphere acidification in root interactions: combining fluorescence with optode techniques. Front. Plant Sci. 4:392. doi: 10.3389/fpls.2013.00392

Fedorova, E., Thomson, R., Whitehead, L. F., Maudoux, O., Udvardi, M. K., and Day, D. A. (1999). Localization of $\mathrm{H}^{+}$-ATPase in soybean root nodules. Planta 209, 25-32. doi: 10.1007/s004250050603

Fenner, B. J., Tiwari, R. P., Reeve, W. G., Dilworth, M. J., and Glenn, A. R. (2004). Sinorhizobium medicae genes whose regulation involves the ActS and/or ActR signal transduction proteins. FEMS Microbiol. Lett. 236, 21-31. doi: 10.1016/j.femsle.2004.05.016

Ferrer, J. L., Austin, M. B., Stewart, C., and Noel, J. P. (2008). Structure and function of enzymes involved in the biosynthesis of phenylpropanoids. Plant Physiol. Biochem. 46, 356-370. doi: 10.1016/j.plaphy.2007.12.009

Fonseca-García, C., Nava, N., Lara, M., and Quinto, C. (2021). An NADPH oxidase regulates carbon metabolism and the cell cycle during root nodule symbiosis in common bean (Phaseolus vulgaris). BMC Plant Biol. 21, 274-290. doi: $10.1186 / \mathrm{s} 12870-021-03060-\mathrm{z}$

Fournier, J., Timmers, A. C. J., Sieberer, B. J., Jauneau, A., Chabaud, M., and Barker, D. G. (2008). Mechanism of infection thread elongation in root hairs of Medicago truncatula and dynamic interplay with associated rhizobial colonization. Plant Physiol. 148, 1985-1995. doi: 10.1104/pp.108.125674

Geddes, B. A., González, J. E., and Oresnik, I. J. (2014). Exopolysaccharide production in response to medium acidification is correlated with an increase in competition for nodule occupancy. Mol. Plant-Microbe Interact. 27, 1307-1317. doi: 10.1094/MPMI-06-14-0168-R

Geddes, B. A., and Oresnik, I. J. (2016). "The mechanism of symbiotic nitrogen fixation," in The Mechanistic Benefits of Microbial Symbionts. Advances in Environmental Microbiology. Vol. 2. C. J. Hurst (Ed.) (Switzerland: Springer International Publishing), 69-97.

Gober, J. W., and Kashket, E. R. (1987). $\mathrm{K}^{+}$regulates bacteroid-associated functions of Bradyrhizobium. Proc. Natl. Acad. Sci. U. S. A. 84, 4650-4654. doi: $10.1073 /$ pnas.84.13.4650

González, J. E., Reuhs, B. L., and Walker, G. C. (1996). Low molecular weight EPS II of rhizobium meliloti allows nodule invasion in Medicago sativa. Proc. Natl. Acad. Sci. U. S. A. 93, 8636-8641. doi: 10.1073/ pnas.93.16.8636

Griffitts, J. S., Carlyon, R. E., Erickson, J. H., Moulton, J. L., Barnett, M. J., Toman, C. J., et al. (2008). A Sinorhizobium meliloti osmosensory twocomponent system required for cyclic glucan export and symbiosis. Mol. Microbiol. 69, 479-490. doi: 10.1111/j.1365-2958.2008.06304.x

Guefrachi, I., Pierre, O., Timchenko, T., Alunni, B., Barrière, Q., Czernic, P., et al. (2015). Bradyrhizobium BclA is a peptide transporter required for bacterial differentiation in Symbiosis with Aeschynomene legumes. Mol. Plant-Microbe Interact. 28, 1155-1166. doi: 10.1094/MPMI-04-15-0094-R

Guerrero-Castro, J., Lozano, L., and Sohlenkamp, C. (2018). Dissecting the acid stress response of rhizobium tropici CIAT 899. Front. Microbiol. 9:846. doi: $10.3389 /$ fmicb. 2018.00846 
Haag, A. F., Baloban, M., Sani, M., Kerscher, B., Pierre, O., Farkas, A., et al. (2011). Protection of Sinorhizobium against host cysteine-rich antimicrobial peptides is critical for symbiosis. PLoS Biol. 9:e1001169. doi: 10.1371/journal. pbio. 1001169

Harrison, J., Jamet, A., Muglia, C. I., Sype, G.Van, De Aguilar, O. M., Puppo, A., et al. (2005). Glutathione plays a fundamental role in growth and symbiotic capacity of Sinorhizobium meliloti. J. Bacteriol. 187, 168-174. doi:10.1128/ JB.187.1.168.

Hartwig, U. A., Maxwell, C. A., Joseph, C. M., and Phillips, D. A. (1990). Effects of alfalfa nod gene-inducing flavonoids on nodABC transcription in rhizobium meliloti strains containing different nodD genes. J. Bacteriol. 172, 2769-2773. doi: 10.1128/jb.172.5.2769-2773.1990

Hassan, S., and Mathesius, U. (2012). The role of flavonoids in root-rhizosphere signalling: opportunities and challenges for improving plant-microbe interactions. J. Exp. Bot. 63, 3429-3444. doi: 10.1093/jxb/err430

Hawkins, J. P., Geddes, B. A., and Oresnik, I. J. (2017). Succinoglycan directly contributes to $\mathrm{pH}$ tolerance in Sinorhizboium meliloti Rm1021. Mol. PlantMicrobe Interact. 30, 1009-1019. doi: 10.1094/MPMI-07-17-0176-R

Heavner, M. E., Qiu, W. G., and Cheng, H. (2015). Phylogenetic co-occurrence of ExoR, ExoS, and ChvI, components of the RSI bacterial invasion switch, suggests a key adaptive mechanism regulating the transition between freeliving and host-invading phases in Rhizobiales. PLoS One 10:e135655. doi: 10.1371/journal.pone.0135655

Heckel, B. C., Tomlinson, A. D., Morton, E. R., Choi, J. H., and Fuqua, C. (2014). Agrobacterium tumefaciens ExoR controls acid response genes and impacts exopolysaccharide synthesis, horizontal gene transfer, and virulence gene expression. J. Bacteriol. 196, 3221-3233. doi: 10.1128/JB.01751-14

Hellweg, C., Pühler, A., and Weidner, S. (2009). The time course of the transcriptomic response of Sinorhizobium meliloti 1021 following a shift to acidic pH. BMC Microbiol. 9, 37-53. doi: 10.1186/1471-2180-9-37

Hirsch, A. M., Lum, M. R., and Downie, J. A. (2001). What makes the rhizobialegume symbiosis so special? Plant Physiol. 127, 1484-1492. doi: 10.1104/ pp.010866

Horváth, B., Domonkos, Á., Kereszt, A., Szűcs, A., Ábrahám, E., Ayaydin, F., et al. (2015). Loss of the nodule-specific cysteine rich peptide, NCR169, abolishes symbiotic nitrogen fixation in the Medicago truncatula dnf7 mutant. Proc. Natl. Acad. Sci. U. S. A. 112, 15232-15237. doi: 10.1073/pnas.1500777112

Howieson, J. G., Ewing, M. A., and D'Antuono, M. F. (1988). Selection for acid tolerance in rhizobium meliloti. Plant Soil 105, 179-188. doi: 10.1007/BF02376781

Hunt, S., King, B. J., Canvin, D. T., and Layzell, D. B. (1987). Steady and nonsteady state gas exchange characteristics of soybean nodules in relation to the oxygen diffusion barrier. Plant Physiol. 84, 164-172. doi: 10.1104/ pp.84.1.164

Hunt, S., and Layzell, D. B. (1993). Gas exchange of legume nodules and the regulation of nitrogenase activity. Annu. Rev. Plant Physiol. Plant Mol. Biol. 44, 483-511. doi: 10.1146/annurev.pp.44.060193.002411

Jamet, A., Mandon, K., Puppo, A., and Hérouart, D. (2007). $\mathrm{H}_{2} \mathrm{O}_{2}$ is required for optimal establishment of the Medicago sativa/Sinorhizobium meliloti symbiosis. J. Bacteriol. 189, 8741-8745. doi: 10.1128/JB.01130-07

Jamet, A., Sigaud, S., Van de Sype, G., Puppo, A., and Herouart, D. (2003). Expression of the bacterial catalase genes during Sinorhizobium melilotiMedicago sativa symbiosis and their crucial role during the infection process. Mol. Plant-Microbe Interact. 16, 217-225. doi: 10.1094/MPMI.2003.16.3.217

Jones, D. L., Dennis, P. G., Owen, A. G., and Van Hees, P. A. W. (2003). Organic acid behavior in soils - misconceptions and knowledge gaps. Plant Soil 248, 31-41. doi: 10.1023/A:1022304332313

Jones, K. M., Kobayashi, H., Davies, B. W., Taga, M. E., and Walker, G. C. (2007). How rhizobial symbionts invade plants: the Sinorhizobium-Medicago model. Nat. Rev. Microbiol. 5, 619-633. doi: 10.1038/nrmicro1705

Jungk, A. O. (2002). "Dynamics of nutrient movement at the soil root interface," in Plant Roots. The Hidden Half. U. Kafkafi, Y. Waisel and A. Eshel (Eds.) (United States: CRC Press), 587-616.

Kannenberg, E. L., and Brewin, N. J. (1989). Expression of a cell surface antigen from rhizobium leguminosarum 3841 is regulated by oxygen and pH. J. Bacteriol. 171, 4543-4548. doi: 10.1128/jb.171.9.4543-4548.1989

Kawaharada, Y., Kelly, S., Nielsen, M. W., Hjuler, C. T., Gysel, K., Muszyński, A., et al. (2015). Receptor-mediated exopolysaccharide perception controls bacterial infection. Nature 523, 308-312. doi: 10.1038/nature14611
Keating, D. H., Willits, M. G., and Long, S. R. (2002). A Sinorhizobium meliloti lipopolysaccharide mutant altered in cell surface sulfation. J. Bacteriol. 184, 6681-6689. doi: 10.1128/JB.184.23.6681

Király, Z., El-Zahaby, H. M., and Klement, Z. (1997). Role of extracellular polysaccharide (EPS) slime of plant pathogenic bacteria in protecting cells to reactive oxygen species. J. Phytopathol. 145, 59-68. doi: 10.1111/j.1439-0434.1997.tb00365.x

Lehman, A. P., and Long, S. R. (2013). Exopolysaccharides from Sinorhizobium meliloti can protect against $\mathrm{H}_{2} \mathrm{O}_{2}$-dependent damage. J. Bacteriol. 195, 5362-5369. doi: 10.1128/JB.00681-13

Lelpi, L., Dylan, T., Ditta, G. S., Helinski, D. R., and Stanfield, S. W. (1990). The ndvB locus of rhizobium meliloti encodes a $319-\mathrm{kDa}$ involved in the production of $\beta$-(1-2)-glucan. J. Biol. Chem. 265, 2643-2651.

Li, L., Jia, Y., Hou, Q., Charles, T. C., Nester, E. W., and Pan, S. Q. (2002). A global $\mathrm{pH}$ sensor: agrobacterium sensor protein $\mathrm{ChvG}$ regulates acidinducible genes on its two chromosomes and Ti plasmid. Proc. Natl. Acad. Sci. U. S. A. 99, 12369-12374. doi: 10.1073/pnas.192439499

Liang, Y., Cao, Y., Tanaka, K., Thibivilliers, S., Wan, J., Choi, J., et al. (2013). Nonlegumes respond to Rhizobial nod factors by suppressing the innate immune response. Science 341, 1384-1387. doi: 10.1126/science.1242736

Lohar, D. P., Haridas, S., Gantt, J. S., and VandenBosch, K. A. (2007). A transient decrease in reactive oxygen species in roots leads to root hair deformation in the legume-rhizobia symbiosis. New Phytol. 173, 39-49. doi: 10.1111/j.1469-8137.2006.01901.x

Lohar, D. P., Sharopova, N., Endre, G., Peñuela, S., Samac, D., Town, C., et al. (2006). Transcript analysis of early nodulation events in Medicago truncatula. Plant Physiol. 140, 221-234. doi: 10.1104/pp.105.070326.1

Lu, H. Y., Luo, L., Yang, M. H., and Cheng, H.-P. (2012). Sinorhizobium meliloti ExoR is the target of periplasmic proteolysis. J. Bacteriol. 194, 4029-4040. doi: 10.1128/JB.00313-12

Madsen, E. B., Madsen, L. H., Radutoiu, S., Olbryt, M., Rakwalska, M., Szczyglowski, K., et al. (2003). A receptor kinase gene of the LysM type is involved in legume perception of rhizobial signals. Nature 425, 637-640. doi: $10.1038 /$ nature02045

Maillet, F., Fournier, J., Mendis, H. C., Tadege, M., Wen, J., Ratet, P., et al. (2020). Sinorhizobium meliloti succinylated high-molecular-weight succinoglycan and the Medicago truncatula LysM receptor-like kinase MtLYK10 participate independently in symbiotic infection. Plant J. 102, 311-326. doi: 10.1111/tpj.14625

Maroti, G. G., Kereszt, A., Kondorosi, E., and Mergaert, P. (2011). Natural roles of antimicrobial peptides in microbes, plants and animals. Res. Microbiol. 162, 363-374. doi: 10.1016/j.resmic.2011.02.005

Mendis, H. C., Madzima, T. F., Queiroux, C., and Jones, K. M. (2016). Function of succinoglycan polysaccharide in Sinorhizobium meliloti host plant invasion depends on succinylation, not molecular weight. MBio 7:e00606-16. doi: 10.1128/mBio.00606-16

Mergaert, P., Nikovics, K., Kelemen, Z., Maunoury, N., Vaubert, D., Kondorosi, A., et al. (2003). A novel family in Medicago truncatula consisting of more than 300 nodule-specific genes coding for small, secreted polypeptides with conserved cysteine motifs. Plant Physiol. 132, 161-173. doi: 10.1104/ pp.102.018192

Mergaert, P., Uchiumi, T., Alunni, B., Evanno, G., Cheron, A., Catrice, O., et al. (2006). Eukaryotic control on bacterial cell cycle and differentiation in the rhizobium-legume symbiosis. Proc. Natl. Acad. Sci. U. S. A. 103, 5230-5235. doi: 10.1073/pnas.0600912103

Miller, K. J., Kennedy, E. P., and Reinhold, V. N. (1986). Osmotic adaptation by gram-negative bacteria: possible role for periplasmic oligosaccharides. Science 231, 48-51. doi: 10.1126/science.3941890

Miller, K. J., and Wood, J. M. (1996). Osmoadatptation by rhizosphere bacteria. Annu. Rev. Microbiol. 6:e23307. doi: 10.1371/journal.pone.0023307

Miller-Williams, M., Loewen, P. C., and Oresnik, I. J. (2006). Isolation of salt-sensitive mutants of Sinorhizobium meliloti strain Rm1021. Microbiology 152, 2049-2059. doi: 10.1099/mic.0.28937-0

Muglia, C. I., Grasso, D. H., and Aguilar, O. M. (2007). Rhizobium tropici response to acidity involves activation of glutathione synthesis. Microbiology 153, 1286-1296. doi: 10.1099/mic.0.2006/003483-0

Mylona, P., Pawlowski, K., and Bisseling, T. (1995). Symbiotic nitrogen fixation. Plant Cell 7, 869-885. doi: 10.1097/00010694-199511000-00009 
Nagpal, P., Khanuja, S. P., and Stanfield, S. W. (1992). Suppression of the ndv mutant phenotype of rhizobium meliloti by cloned exo genes. Mol. Microbiol. 6, 479-488. doi: 10.1111/j.1365-2958.1992.tb01492.x

Ojeda, K. J., Simonds, L., and Noel, K. D. (2013). Roles of predicted glycosyltransferases in the biosynthesis of the rhizobium etli CE3 $\mathrm{O}$ antigen. J. Bacteriol. 195, 1949-1958. doi: 10.1128/JB.02080-12

Oldroyd, G. E. D. (2013). Speak, friend, and enter: signalling systems that promote beneficial symbiotic associations in plants. Nat. Rev. Microbiol. 11, 252-263. doi: $10.1038 /$ nrmicro2990

Oldroyd, G. E. D., and Downie, J. A. (2008). Coordinating nodule morphogenesis with rhizobial infection in legumes. Annu. Rev. Plant Biol. 59, 519-546. doi: 10.1146/annurev.arplant.59.032607.092839

Oldroyd, G. E. D., Murray, J. D., Poole, P. S., and Downie, J. A. (2011). The rules of engagement in the legume-rhizobial symbiosis. Annu. Rev. Genet. 45, 119-144. doi: 10.1146/annurev-genet-110410-132549

Pauly, N., Pucciariello, C., Mandon, K., Innocenti, G., Jamet, A., Baudouin, E., et al. (2006). Reactive oxygen and nitrogen species and glutathione: key players in the legume-rhizobium symbiosis. J. Exp. Bot. 57, 1769-1776. doi: $10.1093 /$ jxb/erj184

Penterman, J., Abo, R. P., De Nisco, N. J., Arnold, M. F. F., Longhi, R., Zanda, M., et al. (2014). Host plant peptides elicit a transcriptional response to control the Sinorhizobium meliloti cell cycle during symbiosis. Proc. Natl. Acad. Sci. U. S. A. 111, 3561-3566. doi: 10.1073/pnas.1400450111

Pérez-Montaño, F., del Cerro, P., Jiménez-Guerrero, I., López-Baena, F. J., Cubo, M. T., Hungria, M., et al. (2016). RNA-seq analysis of the rhizobium tropici CIAT 899 transcriptome shows similarities in the activation patterns of symbiotic genes in the presence of apigenin and salt. BMC Genomics 17, 198-111. doi: 10.1186/s12864-016-2543-3

Pierre, O., Engler, G., Hopkins, J., Brau, F., Boncompagni, E., and Hérouart, D. (2013). Peribacteroid space acidification: A marker of mature bacteroid functioning in Medicago truncatula nodules. Plant Cell Environ. 36, 2059-2070. doi: $10.1111 /$ pce. 12116

Pueppke, S. G., and Broughton, W. J. (1999). Rhizobium sp. strain NGR234 and R. fredii USDA257 share exceptionally broad, nested host ranges. Mol. Plant-Microbe Interact. 12, 293-318. doi: 10.1094/MPMI.1999.12.4.293

Puppo, A., Pauly, N., Boscari, A., Mandon, K., and Brouquisse, R. (2013). Hydrogen peroxide and nitric oxide: key regulators of the legume-rhizobium and mycorrhizal symbioses. Antioxid. Redox Signal. 18, 2202-2219. doi: 10.1089/ars.2012.5136

Pusztahelyi, T. (2018). Chitin and chitin-related compounds in plant-fungal interactions. Mycology 9, 189-201. doi: 10.1080/21501203.2018.1473299

Ramu, S. K., Peng, H. M., and Cook, D. R. (2002). Nod factor induction of reactive oxygen species production is correlated with expression of the early nodulin gene rip1 in Medicago truncatula. Mol. Plant-Microbe Interact. 15, 522-528. doi: 10.1094/MPMI.2002.15.6.522

Reeve, W. G., Dilworth, M. J., Tiwari, R. P., and Glenn, A. R. (1997). Regulation of exopolysaccharide production in rhizobium leguminosarum biovar viciae WSM710 involves exoR. Microbiology 143, 1951-1958. doi: 10.1099/00221287-143-6-1951

Reuber, T. L., Urzainqui, A., Glazebrook, J., Reed, J. W., and Walker, G. C. (1990). Genetic analyses and manipulations of rhizobium meliloti exopolysaccharides. Nov. Biodegrad. Microb. Polym. 12, 285-294. doi: 10.1007/978-94-009-2129-0_24

Reyes-González, A., Talbi, C., Rodríguez, S., Rivera, P., Zamorano-Sánchez, D., and Girard, L. (2016). Expanding the regulatory network that controls nitrogen fixation in Sinorhizobium meliloti: elucidating the role of the two-component system hFixL-FxkR. Microbiology 162, 979-988. doi: 10.1099/mic.0.000284

Riccillo, P. M., Muglia, C. I., De Bruijn, F. J., Roe, A. J., Booth, I. R., and Aguilar, O. M. (2000). Glutathione is involved in environmental stress responses in rhizobium tropici, including acid tolerance. J. Bacteriol. 182, 1748-1753. doi: 10.1128/JB.182.6.1748-1753.2000

Rutten, P. J., Steel, H., Hood, G. A., Ramachandran, V. K., McMurtry, L., Geddes, B., et al. (2021). Multiple sensors provide spatiotemporal oxygen regulation of gene expression in a rhizobium-legume symbiosis. PLoS Genet. 17:e1009099. doi: 10.1371/journal.pgen.1009099

Santos, R., Hérouart, D., Sigaud, S., Touati, D., and Puppo, A. (2001). Oxidative burst in alfalfa- Sinorhizobium meliloti symbiotic interaction. Mol. PlantMicrobe Interact. 14, 86-89. doi: 10.1094/MPMI.2001.14.1.86

Schopfer, C. R. (1999). The male determinant of self-incompatibility in brassica. Science 286, 1697-1700. doi: 10.1126/science.286.5445.1697
Shaw, S. L., and Long, S. R. (2003). Nod factor inhibition of reactive oxygen efflux in a host legume. Plant Physiol. 132, 2196-2204. doi: 10.1104/ pp.103.021113

Smith, L. T., Allaith, A. A., and Smith, G. M. (1994). Mechanism of osmotically regulated $\mathrm{N}$-acetylglutaminylglutamine amide production in rhizobium meliloti. Plant Soil 161, 103-108. doi: 10.1007/BF02183090

Streng, A., Op Den Camp, R., Bisseling, T., Geurts, R., Camp, R.Den, Bisseling, T., et al. (2011). Evolutionary origin of rhizobium nod factor signaling. Plant Signal. Behav. 6, 1510-1514. doi:10.4161/psb.6.10.17444.

Tang, Y., and Hollingsworth, R. I. (1998). Regulation of lipid synthesis in Bradyrhizobium japonicum: low oxygen concentrations trigger phosphatidylinositol biosynthesis. Appl. Environ. Microbiol. 64, 1963-1966. doi: 10.1128/AEM.64.5.1963-1966.1998

Tóth, K., and Stacey, G. (2015). Does plant immunity play a critical role during initiation of the legume-rhizobium symbiosis? Front. Plant Sci. 06, 401-408. doi: $10.3389 /$ fpls.2015.00401

Van de Velde, W., Zehirov, G., Szatmari, A., Debreczeny, M., Ishihara, H., Kevei, Z., et al. (2010). Plant peptides govern terminal differentiation of bacteria in symbiosis. Science 327, 1122-1126. doi: 10.1126/science.1184057

Via, V. D., Zanetti, M. E., and Blanco, F. (2016). How legumes recognize rhizobia. Plant Signal. Behav. 11:e1120396. doi: 10.1080/15592324.2015.1120396

Virts, E. L., Stanfield, S. W., Helinski, D. R., and Ditta, G. S. (1988). Common regulatory elements control symbiotic and microaerobic induction of nifA in rhizobium meliloti. Proc. Natl. Acad. Sci. U. S. A. 85, 3062-3065. doi: 10.1073/pnas.85.9.3062

Winkel-Shirley, B. (2001). Flavonoid biosynthesis. A colorful model for genetics, biochemistry, cell biology, and biotechnology. Plant Physiol. 126, 485-493. doi: $10.1104 /$ pp.126.2.485

Yancey, P. H., Clark, M. E., Hand, S. C., Bowlus, R. D., and Somero, G. N. (1982). Living with water stress: evolution of osmolyte systems. Science 217, 1214-1222. doi: $10.1126 /$ science.7112124

Yao, S. Y., Luo, L., Har, K. J., Becker, A., Rüberg, S., Yu, G. Q., et al. (2004). Sinorhizobium meliloti ExoR and ExoS proteins regulate both succinoglycan and flagellum production. J. Bacteriol. 186, 6042-6049. doi: 10.1128/ JB.186.18.6042-6049.2004

York, W. S., McNeil, M., Darvill, A. G., and Albersheim, P. (1980). Beta-2linked glucans secreted by fast-growing species of rhizobium. J. Bacteriol. 142, 243-248. doi: 10.1128/jb.142.1.243-248.1980

York, G. M., and Walker, G. C. (1997). The rhizobium meliloti exoK gene and $\mathrm{prsD} / \mathrm{prsE} / \mathrm{exsH}$ genes are components of independent degradative pathways which contribute to production of low-molecular-weight succinoglycan. Mol. Microbiol. 25, 117-134. doi: 10.1046/j.1365-2958.1997.4481804.x

Zamorano-Sánchez, D., and Girard, L. (2015). "FNR-like proteins in rhizobia: past and future," in Biology Nitrogen Fixation. F. J. Brujin (Ed.) (United States: John Wiley \& Sons), 155-166.

Zhou, P., Silverstein, K. A., Gao, L., Walton, J. D., Nallu, S., Guhlin, J., et al. (2013). Detecting small plant peptides using SPADA (small peptide alignment discovery application). BMC Bioinfo. 14, 335-351. doi: 10.1186/1471-2105-14-335

Zipfel, C., and Oldroyd, G. E. D. (2017). Plant signalling in symbiosis and immunity. Nature 543, 328-336. doi: 10.1038/nature22009

Conflict of Interest: The authors declare that the research was conducted in the absence of any commercial or financial relationships that could be construed as a potential conflict of interest.

Publisher's Note: All claims expressed in this article are solely those of the authors and do not necessarily represent those of their affiliated organizations, or those of the publisher, the editors and the reviewers. Any product that may be evaluated in this article, or claim that may be made by its manufacturer, is not guaranteed or endorsed by the publisher.

Copyright (c) 2022 Hawkins and Oresnik. This is an open-access article distributed under the terms of the Creative Commons Attribution License (CC BY). The use, distribution or reproduction in other forums is permitted, provided the original author(s) and the copyright owner(s) are credited and that the original publication in this journal is cited, in accordance with accepted academic practice. No use, distribution or reproduction is permitted which does not comply with these terms. 